\title{
Support For Areas With Low Level Of Electromobility Through The Use Of Big Data
}

\author{
Grzegorz Sierpiński \\ Silesian University of Technology, Faculty of Transport \\ Krasińskiego 8 Street, 40-019 Katowice, Poland \\ grzegorz.sierpinski@polsl.pl
}

\begin{abstract}
Major challenges for the future transport systems include, inter alia, the reduction of emissions and reasonable energy management. To this end, one of actions popular in recent years is the development of electromobility in cities. This development is often difficult because of the social and infrastructure barriers. The article presents the method that enables to develop electromobility in cities which have a negligible number of charging station. The method is based on new technologies (in this case, multimodal trip planner developed in the framework of an international project Electric Travelling in ERA-NET CoFund Electric Mobility Europe) and acquisition of Big Data determining directly the needs of people travelling. Information gathered can provide a relevant decision-making support while determining the location of charging stations with the objective of promoting electric vehicles.
\end{abstract}

Keywords: Electromobility, charging points location, sustainable development, travel behaviour, Big Data.

\section{Introduction}

Energy consumption is one of the main problems of the contemporary world both in relation to the industry, services, life and transport. In many countries, current rapid changes associated with the development of electromobility aim at reducing emissions and the introduction of responsible management of energy consumption [1].

Changes in behaviour of people travelling are not easy and fast [2]. They require a proper approach and smart measures. For this reason, it is important to develop a relevant strategy to introduce those changes in coming years. The implementation of electromobility is possible by overcoming transport infrastructure and socio-economic barriers. When examining the development of electromobility, we may distinguish three levels of urban development:

- High level - a high density network of charging stations with a flexible approach to changes in the case of new traffic generators (areas attracting traffic)

- Intermediate level - applies to cities with existing charging stations network, however insufficient comparing to the actual needs

- Low level - applies to cities with few charging stations, which prevents promotion of electromobility.

For the purpose of the international project "Electric travelling - platform is the support the implementation of electromobility in Smart Cities based on ICT applications" within the scope of the ERA-NET CoFund Electric Mobility Europe Programme [3], three European cities were selected to examine the current status and to implement the final product of the project - an ICT application supporting the development of electromobility. Summary of existing charging infrastructure for electrical cars (Fig. 1) for three Implementation Partners (Hague, Budapest and Sosnowiec) shows significant differences in the degree of implementation of electromobility (density and number of charging stations in city).

For cities with a low level of electromobility, particularly important is the location of the first charging stations. The goal is to start building trust in using electric cars. Therefore, the location should be consistent with the needs of people travelling to maximize the effect and promote electromobility. 

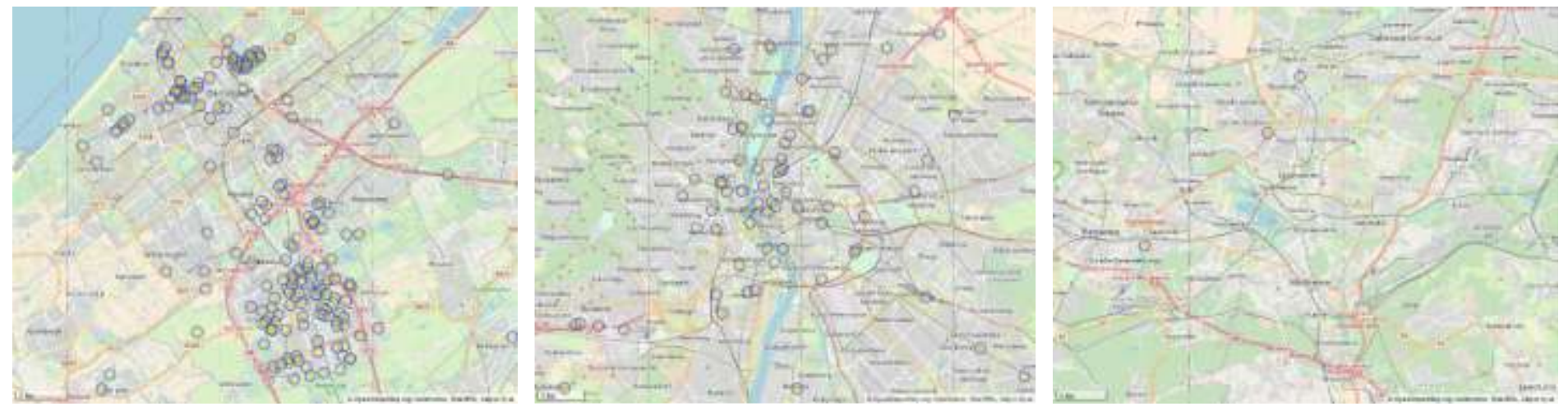

Fig. 1. Implementation Partner Areas with charging stations for electrical vehicles: a/ Hague, b/ Budapest, c/ Sosnowiec Source OpenStreetMap and Overpass service.

Transport preferences have a significant impact on the functioning of the transport system and in general a city or a region. Appropriate modal split (with emphasis on green solutions [4] [5], including travels using electric cars) requires support for such preferences. This is possible through various organizational, legal and infrastructure activities [6]. At the same time, mobility needs must be taken into account when changes are introduced [7]. Only such a course of action promotes sustainable development [8],[9]. Modern technology provides many possibilities of collecting information [10]. In recent years, major progress in on-line trip planners promotes their use by citizens [11],[12],[13]. The increase of interest has been used to develop a method of data acquisition regarding travelling mobility needs to support further implementation of electromobility in cities. Advantages of the tools include its versatility in terms of the area and the lack of additional cost.

\section{Proposed method}

The research project developed the ETSys system which supports the development of electromobility in cities. The support is addressed to the administration of the city and the transport system (local authorities), as well as directly to people travelling. The system includes a trip planner. The planner is a tool that helps to determine an optimal route for one of 11 modes to travel, and provides the person travelling with information about the impact on the environment related to the trip. In this way, the user is able to compare trips, e.g. traditional passenger vehicle and electric car. In planner encompasses four trip planning criteria. Apart from the traditional time and distance, the route can be selected based on cost and reduction of the environmental impact.

The method for the acquisition of information about the needs of travellers also includes a specific "Big Data" structure. The database can be used in the system for forecasting future requirements of charging stations and as a support in decisionmaking on changes of transport systems. By sending a $Q_{i}$ query, the user provides basic information about the trip. Thus, registered queries comprise the database (1):

$$
Q=\left\{Q_{1}, Q_{2}, Q_{3}, \ldots, Q_{n},\right\}
$$

where:

$Q$ - set of all queries to the planner

$Q_{i}$ - selected $i$ query

Specific queries are sets of a specified number of elements containing all defined features of a trip. (2) lists only selected features:

$$
Q_{i}=\left\{I P_{i}, D A T E_{i}, T_{I M E_{i}}, O R_{i}, D E S T_{i}, M O D E_{i}, O P T_{i}, M_{O T I V}, \ldots\right\}
$$


Registered trip parameters include the date $\left(D A T E_{i}\right)$, planned start time $\left(T I M E_{i}\right)$, geographical coordinates of the start $\left(O R_{i}\right)$ and the end of the trip $\left(D E S T_{i}\right)$, mode $\left(M O D E_{i}\right.$, one of the 11 options), optimization criteria $\left(O P T_{i}\right.$ important for the user), motivation $\left(M_{O} O T V_{i}\right)$ and other parameters of the trip and selected means of transport, e.g. maximum distance for the person travelling while cycling or walking, parameters of the electric vehicle used etc.

Such a database allows you to identify POIs while using a passenger car as a first step to decide about the location of charging stations for eclectic vehicles. Of course, important features which support a specific location include parameters of the power network, location parking places, management of urban space etc. However, information about actual needs, especially for cities that start the implementation of electromobility, can be an important added value in the decision-making process.

It should be noted that the database includes also the motivation to travel. Motivation is defined as a couple of parameters related to the origin point and the destination, e.g. home, work, education, and shopping, business, health, official matters, sports and recreation, entertainment and other. Through filtering data, the Big Data Set, developed during the operation of the planner, identifies several different needs as regards charging stations:

- locations related to the option house, once put on the settlement map, help to identify areas of multi-family houses (housing estates). Such locations frequently lack private garages and therefore there is a need to charge an electrical vehicle at the parking place next to a building. At the same time, there is no need to have fast charging facilities.

- options work and education (in case of using individual cars) indicate the need for a longer term parking at such locations. Thus, charging stations are important due to repeated nature of parking (daily trips to work or school). Consequently, charging time is not so important, though the stay is usually shorter than in the first option

- other options require more analysis and data aggregation to determine priority locations and their ranking list. Parking related to shopping or recreation involves the shortest stay of a person travelling. In such locations, it is particularly important to install fast charging stations.

Filtering of data may therefore be carried out according to trip start and destination, as well as the purpose of travelling (3):

where:

$$
\{q \in Q: W(q)\}
$$

$W(q)$ - logical condition supporting data filtering algorithm.

\section{Expected changes in cities}

As a result of the data acquisition technique, it is possible to support decision-making bodies in the city to determine locations for charging stations. The increase in the number of charging stations, provided their locations are optimised, will be one of incentives for people travelling [14] to change the way their travel and increase the use of electric cars.

The development of charging stations for electric cars in specific areas of the city is an important signal for drivers that changes are unavoidable. This also promotes the designation of green zones accessible for green vehicles only. In the longer term, the expected impact of measures related to the development of charging stations in line with the needs of the people travelling includes:

- Improvement of transport systems according to actual needs of people travelling based on the Big Data collected from users of the system

- Increased number of electric vehicle users due to overcoming barriers related to the perception of electric vehicles from the point of view of their limited range, poor infrastructure etc.

- Increased the number of people aware of the impact of transport on the environment who change their travelling behaviour towards more environmentally friendly solutions, and improved social acceptance of electromobility

- Reduced pollution and noise in urban areas (improved air quality, reduced noise and promotion of economic growth by increased use of electric cars). 


\section{Conclusion and further research}

The support is designed to reduce emission from traditional passenger cars and at the same time help to promote rational use of resources by building of charging station in locations justified by their subsequent use.

Preliminary results confirm that data from queries can be used to improve the functioning of the transport system. These data reflect the real needs of people in the field of travel. The application of the proposed method in a single trip planner can bring the desired effect only in case the planner becomes very popular. However, the approach can be used in the future through standardization data and their aggregation to meet global ITS standards [15].

\section{Acknowledgements}

The present research has been financed from the means of the National Centre for Research and Development as a part of the international project within the scope of ERA-NET CoFund Electric Mobility Europe Programme "Electric travelling - platform to support the implementation of electromobility in Smart Cities based on ICT applications".
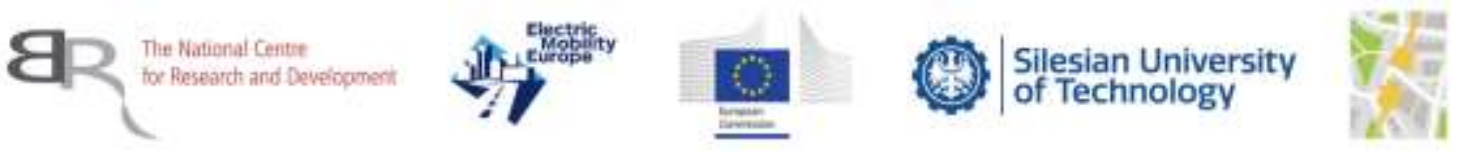

\section{References}

[1] Clean Power for Transport: A European alternative fuels strategy, $\operatorname{COM(2013),~} 17$.

[2] K. Choocharukul, H.T. Van, S. Fujii, "Psychological effects of travel behavior on preference of residential location choice," Transportation Research Part A, vol. 42, pp. 116-124, 2008.

[3] Electric travelling - platform to support the implementation of electromobility in Smart Cities based on ICT applications - Project proposal under EMEurope Programme, 2016.

[4] M. Jacyna, J. Żak, I. Jacyna-Gołda, J. Merkisz, A. Merkisz-Guranowska, J. Pielucha, "Selected aspects of the model of proecological transport system," Journal of KONES, Powertrain and Transport, vol. 20, pp. 193-202, 2013.

[5] E. Macioszek, "First and last mile delivery - problems and issues," Advances in Intelligent Systems and Computing, vol. 631, pp. 147-154, 2018.

[6] J. Stanley, "Land use/transport integration: Starting at the right place," Research in Transportation Economics, vol. 48, 381-388, 2014.

[7] M. Staniek, E. Macioszek, G. Sierpiński, "Travel planning concept taking road infrastructure condition into account," Proceedings of the 2nd World Congress on Civil, Structural, and Environmental Engineering, Barcelona, 2017, Paper No. ICTE 123.

[8] Our Common Future. Report of the World Commission on Environment and Development, 1987.

[9] D. Banister, "The sustainable mobility paradigm," Transport Policy, vol. 15, pp. 73-80, 2008.

[10] S. Iwan S., K. Małecki, "Data Flows in an Integrated Urban Freight Transport Telematic System," Communications in Computer and Information Science, vol. 329, pp. 79-86, 2012.

[11] P. Borkowski, "Towards an Optimal Multimodal Travel Planner-Lessons from the European Experience," Advances in Intelligent Systems and Computing, vol. 505, pp. 163-174, 2017.

[12] I. Celiński, G. Sierpiński, M. Staniek, "Sustainable development of the transport system through rationalization of transport tasks using a specialised travel planner," in: Transport Infrastructure and Systems, G. Dell'Acqua, F. Wegman, Eds. London: CRC Press, Taylor \& Francis Group, 2017, pp. 1071-1079.

[13] D. Jaunzems, A. Lektauers, "Suitability Analysis of Routing Algorithms for Web-based Transportation Planning," Information Technology and Management Science, vol. 16, pp. 79-84, 2013.

[14] M.D. Meyer, "Demand management as an element of transportation policy: using carrots and sticks to influence travel behavior," Transportation Research Part A, vol. 33, pp. 575-599, 1999.

[15] G. Sierpiński, M. Staniek, E. Macioszek, "Standardisation of travel planners and use of a return channel," Proceedings of the 2nd World Congress on Civil, Structural, and Environmental Engineering, Barcelona, 2017, Paper No. ICTE 121. 